\title{
The Impact of Future Time Perspective and Personality on the Sustainable Behaviours of Seniors
}

\author{
Jacqueline K Eastman, Georgia Southern University \\ Pratik Modi, Institute of Rural Management \\ Sianne Gordon-Wilson, University of Portsmouth
}

\begin{abstract}
This study examined a national sample of American seniors to determine the influence of future time perspective (FTP) and personality traits on their sustainable behaviours. Based on a sample of 520 seniors, the study found a significant positive relationship between FTP and sustainable behaviours. FTP fully mediates the impact of the conscientiousness personality trait on sustainable behaviours and partially mediates the impact of the openness and agreeableness personality traits on seniors' sustainable behaviours. The results contribute to the extant literature by explaining that the three personality traits influence sustainable behaviours through seniors' future time perspective. The results suggested the need for policy to focus on seniors' future time perspective and to prioritise more conscientious, open, and agreeable personality traits when encouraging American seniors to adopt sustainable behaviours.
\end{abstract}

\section{INTRODUCTION}

This research focuses on the "demand-side" of sustainable behaviour by focusing on consumers' sustainable behaviours. There is the assumption that consumers understand their role within sustainability and will adapt their consumption habits accordingly (Gandenberger et al. 2011; Thøgersen 2005); however, this development has been relatively small within sustainable consumption (Thøgersen 2005; Thøgersen and Crompton 2009) because consumers perceive it as being too lengthy, expensive, and demanding (Valor 2008). The end goal of consumer policy is to encourage consumers to adopt sustainable behaviours, so it becomes a normalised and a natural part of their daily lives. "Understanding which consumers are more likely to respond positively to different sorts of policies and appeals, and which are not, is clearly important to policymakers. However, just as important is understanding why different consumers respond differently" (Luchs and Mooradian 2012, pp. 138).

By using a national sample comprised of American seniors, our research builds on the research on personality and seniors' sustainability done by Gordon-Wilson and Modi (2015), and the work of Desochers et al. (2019), and Luchs and Mooradian (2012) through further examination of the impact of gender and personality on sustainable behaviour (SB). Due to the literature containing inconsistent findings with demographic variables impacting on sustainability (Diamantopoulos et al.2003), we consider future time perspective (FTP) by addressing seniors who think about and plan for the future. Milfont et al. (2012) found that FTP influences consumers' environmental attitudes and behaviours, but the majority of their studies involved student samples rather than seniors. Our research makes a contribution through focusing solely on the senior market in looking 
at FTP and sustainability. Research from psychology and ageing indicates that future time is a better predictor of consumer perceptions, attitudes, and behaviours than chronological age (Kuppelwieser and Sarstedt 2015). The literature suggests that seniors tend to have less of a FTP than younger people (Fung and Isaacowitz 2016). We test if this holds for sustainable behaviour among seniors. This research specifically examines if seniors' personality and social experience of time impact their sustainable behaviours and provides suggestions based on these findings for public policy makers for inducing sustainability behaviours.

The research contributes to the literature through better understanding seniors' sustainable behaviour and if personality, with their perception of time, impacts their sustainable behaviours. We consider this to be important as people are living longer than ever before (BBC News 2019), and this has clear links to temporality. Focusing on seniors' sustainability behaviour through the lens of FTP and personality makes a contribution as it aids in segmenting and positioning sustainability for the senior market that goes beyond demographics. Given that America produces the second-highest amount of carbon dioxide emissions in the world (EDGAR 2017), looking at the US market is of value to public policymakers. "U.S. households account for around 38\% of national carbon emissions through their direct actions, a level of emissions greater than that of any country except China and larger than the entire U.S. industrial sector" (Gardner and Stern 2008, pp. 13). Americans' adoption of more sustainable behaviours will, therefore, benefit consumers at large and the planet. Thus, by gaining a better understanding of the motivation and context in which American seniors perform sustainable behaviours, this research will guide public policy in crafting better strategies to encourage sustainable changes in private households. Research suggests a small positive relationship between age and sustainable behaviours (Wiernik et al. 2016) when explaining older consumers' sustainable behaviours. For example, Gordon-Wilson and Modi (2015) found that seniors' level of sustainable behaviour increased with chronological age in the UK, but this was not found to be significant. Chronological age has been criticised for being a restrictive and unidimensional variable that neglects "the personal experiences of ageing as living in time" (Baars 2010, pp. 374). According to Socioemotional Selectivity Theory (SST), younger consumers tend to have an expansive time view and a more active social life, whereas older people have a limited time perception (Wei et al. 2013). Research suggests "the anticipation of time plays an important role in social cognition and social behaviour" (Carstensen et al. 1999, pp. 175). Socioemotional Selectivity Theory (SST) is utilised as the theory to explain the relationship between time and sustainable behaviours because it can explain the differences beyond age that can impact people's behaviour (GordonWilson and Modi 2015). SST suggests time perception that impacts human motivation and the goals people pursue (Carstensen et al. 1999). Those who perceive time to be expansive will focus on future, more knowledge-oriented goals, while those who perceive time to be limited will focus on more emotional-oriented goals (Carstensen et al. 1999). This research proposes that seniors who see themselves as having more time in their lives will exhibit more sustainable behaviours and that this relationship will be stronger for those with a future time perspective.

Seniors are defined in this study as those aged 50 years and above, which is the consensus among gerontologists, academics, and practitioners (Guiot 2001; Kohlbacher et al. 2011; Riley et al. 2012; Sudbury and Simcock 2009). The senior market is an important segment within America as it includes over 100 million individuals with significant financial power, controlling $42 \%$ of the after-tax income with a median income over $\$ 56,000$ (Anderson 2014; Weigelt 2015a) and accounting for half of the consumer spending (Weigelt 2015a). Additionally, the median age of Americans continues to rise (Roberts et 
al. 2018). Although older American consumers represent a lucrative market segment, there is little research on them within consumer marketing (Gregory 2014). Finally, as older consumers indicate a higher environmental burden (Kalbar et al. 2018), focusing on the sustainable behaviours of older consumers can make a more significant impact on society. With the size, the financial, and the environmental impact of American seniors, and the fact that there is little research looking specifically at the sustainable behaviours of seniors, this research will make a significant contribution to public policy by providing a better understanding of what motivates seniors' sustainable behaviours.

The following sections of this paper describe the literature on sustainable behaviour, Socioemotional Selectivity Theory (SST), future time perspective (FTP), personality, and gender, along with the hypotheses. As the paper is grounded in SST, we first present the hypotheses dealing with the direct effect of FTP on sustainability. We then present the hypotheses dealing with personality in terms of a direct effect on sustainability, a direct effect on FTP, and personality being partially mediated by FTP in its effect on sustainability. Our final hypothesis deals with the influence of gender. The methodology, which utilises a sample of 520 American seniors with a Qualtrics panel, is then discussed along with the results of the hypotheses and the theoretical and public policy implications.

\section{LITERATURE REVIEW}

\section{Sustainable Behaviour}

Different actions fall under the umbrella of sustainable behaviour including sustainable consumption involving purchasing products with minimal, reduced, or no harm to the environment, driving less to save energy, and recycling (Roberts 1996). While Americans have increased their adoption of sustainable behaviour, it is still relatively low with only $9 \%$ regularly buying products or packaging made from recycled materials and only $18 \%$ regularly cutting back on their car usage (GFK 2011). This may be because Americans do not feel that they can individually help to improve the environment (GFK 2011), which is also supported by Thøgersen (2005) who holds that only large groups of consumers can make any sustainable difference rather than individual consumers. Hence, consumers may have positive attitudes towards sustainability but do not reflect those attitudes in their consumption (Eckhardt 2010; Finisterra do Paço and Raposo 2010; Gifford and Nilsson 2014; Luchs and Mooradian 2012; Pape et al. 2011). It is therefore essential that sustainable behaviours are measured in terms of reporting on actual behaviours rather than measuring consumers' attitudes or concerns towards them. Robelia and Murphy (2012) found that while Americans had high levels of knowledge about some environmental problems (e.g., what renewable resources were, where rubbish went, and what caused habitat destruction), they had low levels of knowledge about others (such as energy production and water quality).

A market report suggests that a portion of American seniors are willing to recycle $(69 \%)$, use energy-efficient light bulbs (71\%), use energy-efficient windows (42\%), and use ecofriendly cleaning products (20\%) (Anderson 2014), but there are no empirical academic studies, to the authors' knowledge, that have examined seniors' sustainable behaviour and the influence of time. In order to encourage and increase the adoption of sustainable behaviours, there needs to be a better understanding of what may motivate senior Americans' sustainable efforts. While the number of influences impacting proenvironmental behaviour is complex and not one project can encompass all the relevant variables (Gifford and Nilsson 2014), this research contributes by focusing on the US senior market and the influence of time and personality. 


\section{Socioemotional Selectivity Theory (SST)}

SST holds that those who feel they have limited time left tend to be more present-oriented and pursue emotional goals that focus on positive experiences that are immediately rewarding (Carstensen et al. 1999), while those who feel that time is expansive tend to be more future-oriented and pursue knowledge goals with a focus on planning and analysing. Research on SST supports the impact of age among seniors. When individuals age, they become more present-oriented and less future-oriented (Ebner et al.2006; Fung and Isaacowitz 2016; Shipp et al. 2009) because they perceive their time as being more limited (Fung and Isaacowitz 2016; Shipp and Aeon 2019), which is especially pronounced for older seniors (post 65 years old) (Shipp et al. 2009). Research illustrates that seniors make emotion-based judgments and decisions (Löckenhoff et al. 2012) and have stronger recall of emotional information (Barber et al. 2016; Carstensen et al. 1999; Kennedy et al. 2004; Williams and Drolet 2005). These findings demonstrate that seniors show stronger emotional aspects as they increase in age and their future time horizon becomes more limited, which is supported by Carstensen et al. (2011).

Rational appeals, however, have been found to be more effective for those with an expansive time perspective (Williams and Drolet 2005) because they perceive the future as open to opportunities and thus plan for what they can experience and enjoy later in life, along with saving any newly acquired information for when they might need it (Fung and Carstensen 2003). This would suggest that those with a more expansive time perception would be more open to the rational, practical benefits of sustainable behaviours, mainly because "when time is perceived as expansive, long-term goals are chosen over others because they optimize future possibilities" (Carstensten et al. 1999, pp. 178; Shipp and Aeon 2019). Research is needed to examine the impact of seniors' time perspective on sustainability because seniors may be less likely to have the future time perspective needed to encourage sustainability. They therefore require more targeted public policy to encourage them to adopt sustainable behaviours.

\section{Future Time Perspective}

Temporal perspective describes how various aspects of time (past, present, and future time) impact consumers' (Zimbardo and Boyd 1999) "motivation, cognition, and emotion, and therefore how they behave in relation to their specific goals" (Gordon-Wilson and Modi 2015, pp. 3). A past time perspective is when consumers reflect on their previous experiences and events, whereas a present time perspective is directed towards immediate outcomes with consumers living for today and having little consideration for tomorrow (Zimbardo and Boyd 1999). A future time perspective (FTP) directs consumers to strive for future goals and rewards (Zimbardo and Boyd 1999) and may be more beneficial to life outcomes (Shipp and Aeon 2019).

SST shows how one's perception of future time changes with chronological age. Seniors may perceive their time as running out due to being closer to the end of their lives (Shipp and Aeon 2019). Therefore, they may perceive their time as being limited by default, in comparison to younger adults who will view their time as expansive, thereby giving them a tendency to be more future-oriented. Hence, seniors have more of a limited FTP than younger adults (Allemand et al. 2012; Coudin and Lima 2011; Grühn et al. 2016; KotterGrühn et al. 2010; Lang and Carstensen 2002) and therefore think about the present more than the past and future (Grühn et al. 2016). This can be influenced by life situations such as illness, frustration, or economic conditions (Fung et al. 1999). Research suggests a shift 
in time perspective from the future to the present will result in a shift in emphasis from more knowledge-related to more emotionally gratifying motives (Grühn et al. 2016). When looking specifically at sustainable behaviours, research has shown a positive relationship with FTP. Future-oriented consumers are more likely to adopt sustainable behaviours than present-oriented consumers (Milfont et al. 2012; Urien and Kilbourne 2011). Future-oriented consumers behave more responsibly with their use of energy and water when there is a benefit to do so (Carmi 2013) with a positive correlation found between FTP and water conservation (Corral-Verdugo et al. 2006) and the use of public transportation (Joireman et al. 2004). Additionally, research suggests that consumers perceive the environmental aspect of sustainability (e.g., recycling and pollution mitigation) more in terms of cognitive/analytical, long-term, and global considerations compared to the social dimension of sustainability (e.g., fair trade, supporting communities), which is characterised more by affective considerations (Catlin et al. 2017). We therefore expect future-oriented consumers to be more willing to adopt environmentally sustainable behaviours, as this could have a positive and beneficial impact in the long-term. Furthermore, consumers with an expansive time frame would be preparing to benefit from improved sustainable conditions in the future. Conversely, pastoriented consumers may view environmental issues negatively and so are less likely to change their behaviour by adopting sustainable behaviours (Kilbourne et al.2002; Kilbourne and Pickett 2008). Thus, future-oriented seniors would be more likely to exhibit sustainable behaviours as proposed by the following hypothesis:

H1: Those seniors with more of a FTP will exhibit higher levels of sustainable behaviours.

\section{Personality Traits}

Personality traits are dimensions of individual differences that show consistent patterns of thoughts and feelings (McCrae and John 1992). The Big Five framework of personality (neuroticism, extroversion, openness, agreeableness, and conscientiousness) has been frequently utilised in the personality literature (Gosling et al. 2003), and these traits "are considered to represent much of the normal personality domain" (Gifford and Nilsson 2014, p. 143). Furthermore, personality may better explain sustainable attitudes and behaviours than demographics (Luchs and Mooradian 2012).

Research has shown that highly open individuals, who have a higher tolerance for the unfamiliar, are more receptive to new ideas and concepts (Jacques et al. 2009; Kim et al. 2014; Wood 2012). "Openness encompasses qualities such as originality, imagination, and having broad interests" (Desochers et al. 2019, p. 205; John and Srivastava 1999). The openness personality trait is positively related to sustainability (e.g., Gordon-Wilson and Modi 2015; Hirsh 2010; Hirsh and Dolderman 2007; Luchs and Mooradian 2012; Markowitz et al. 2012; Milfont and Sibley 2012; Soliño and Farizo 2014) among seniors (Gordon-Wilson and Modi 2015; Markowitz et al. 2012). Additionally highly conscientious individuals also have traits that one would expect to support sustainable behaviours, which research has supported (e.g., Hirsh 2010; Kim et al. 2014; Kvasova 2015; Milfont and Sibley 2012; Swami et al. 2011). They are reliable, ambitious, organised (McCrae and Costa 1990), thorough, careful, vigilant, and self-disciplined (Verplanken and Sato 2011) with a greater interest in long-term planning (Kim et al. 2014). Luchs and Mooradian (2012) found that the agreeableness personality trait influenced consumers' environmental concerns. Some suggest that this may be because agreeableness addresses consumers' compliance with rules set by others, along with the willingness to compromise one's own needs to get along with others (DeYoung 2010; Kim et al. 2014). Agreeable individuals trust others, are cooperative, and are sympathetic to 
others (Desrochers et al. 2019; John and Srivastava 1999). The literature supports a relationship between openness, agreeableness, conscientiousness, and sustainability (Hirsh 2010; Milfont and Sibley 2012; Nisbet et al. 2009). We offer that this relationship will also exist for seniors. Thus, we propose that those seniors with more agreeable, conscientious, and/or open personality types will exhibit more sustainable behaviours as illustrated in Fig. 1 and hypothesised below:

H2a: Seniors with a more agreeable personality type will exhibit more sustainable behaviours.

H2b: Seniors with a more conscientious personality type will exhibit more sustainable behaviours.

$\mathrm{H} 2 \mathrm{c}$ : Seniors with a more open personality type will exhibit more sustainable behaviours.

Fig. 1

The hypothesised structural model of personality, future time perspective and sustainable behaviours. OPEN openness, CONS conscientiousness, AGRE agreeableness, FTP future time perspective, SB sustainable behaviours

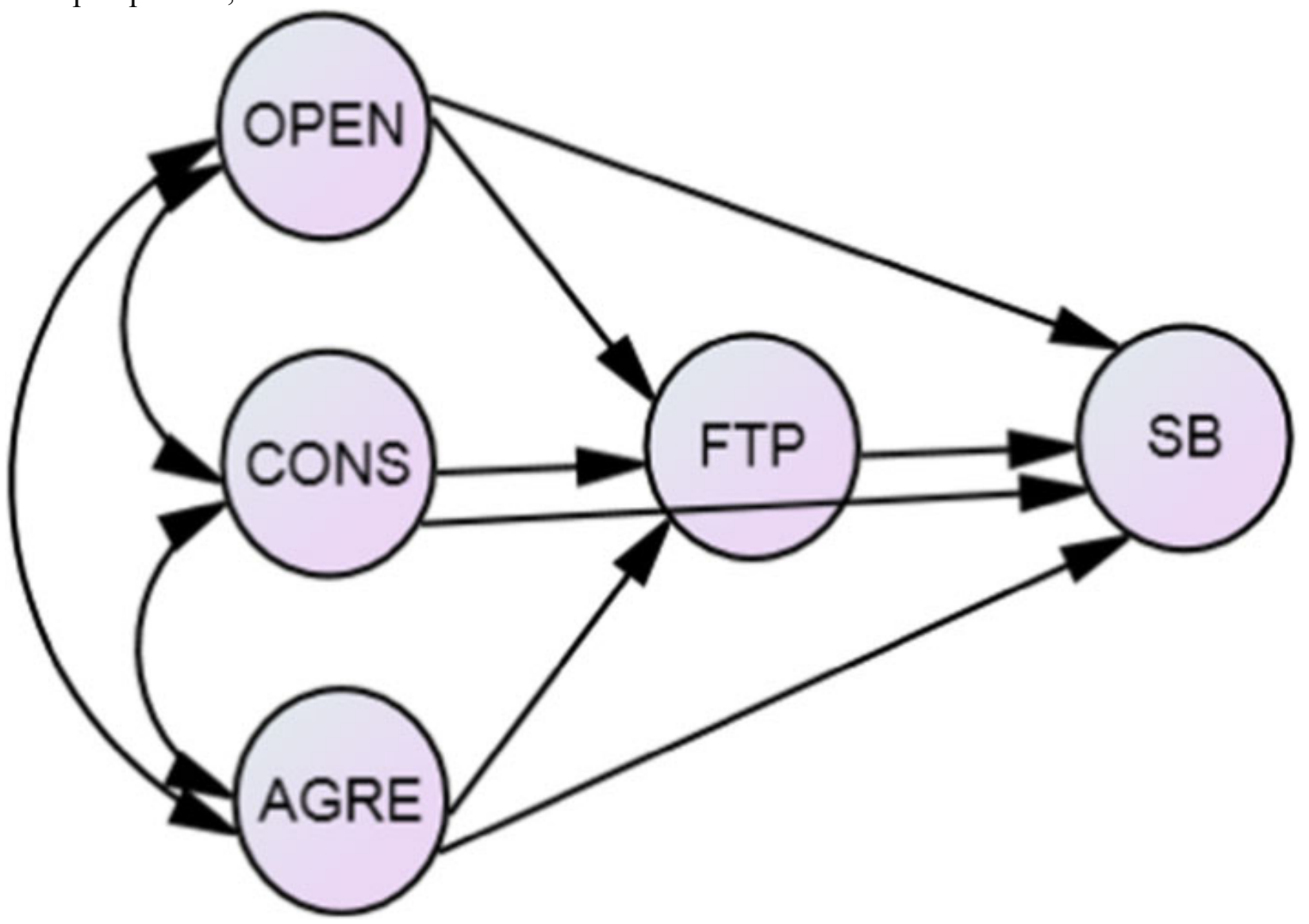

There has been a wide range of studies finding openness, agreeableness, and conscientiousness as the Big 5 personality variables strongly linked to environmental engagement (Gifford and Nilsson 2014; Milfont and Sibley 2012), but there are inconclusive results in the literature between the remaining personality traits (neuroticism and extroversion) and sustainable behaviours. Extroverts are sociable, active, peopleoriented, and talkative (Kim et al. 2014; McCrae and Costa 1990), while neurotic consumers seek immediate gratification (Youn and Faber 2000) and have concerns about how to complete tasks and overcome any obstacles (Jacques et al. 2009). We predict that 
these traits might act as distractions, so these consumers would be less likely to voluntarily adopt sustainable behaviours compared to agreeable, open, and conscientious consumers, and thus are not focusing on them in this study.

Some research has examined how personality relates to perceptions of time found that conscientious individuals are more present and future-oriented (Kim et al. 2014; Shipp et al. 2009; Zimbardo and Boyd 1999), while openness correlates negatively with the present orientation (Zimbardo and Boyd 1999) and agreeableness correlates negatively with a past orientation. In this study, we examine how personality traits relate to FTP. Based on the existing literature, we propose the following hypotheses:

H3a: Seniors with a more agreeable personality type will exhibit more of a future time perspective.

H3b: Seniors with a more conscientious personality type will exhibit more of a future time perspective.

H3c: Seniors with a more open personality type will exhibit more of a future time perspective.

The literature is lacking in examining time perspective and personality traits within the remit of sustainable behaviours. We address this gap by testing to identify if they are connected. Based on the aforementioned literature, we expect future-oriented consumers to be the most willing to adopt sustainable behaviours. Furthermore, those consumers who have agreeable, open, and conscientious personality traits would be more likely to exhibit more sustainable behaviours, and this will be more likely when they have a FTP. Hence, FTP mediates the relationship between these specific personality traits (agreeableness, conscientiousness, and openness) and sustainable behaviours. Thus, we propose the following hypothesis as illustrated in Fig. 1:

H4: Seniors' future time perspective will influence sustainable behaviours such that it will partially mediate the personality traits' effects on sustainable behaviours.

\section{Gender}

While Diamantopoulos et al. (2003) notes inconsistencies with demographic variables impacting sustainability, research finds that gender may be one consistent variable. Specifically, research suggests that females are more concerned about the environment (Carlsson-Kanyama et al. 2010; Xiao and McCright 2015; Zelezny et al. 2000), are more likely to hold sustainable attitudes (Dietz et al. 2002; Luchs and Mooradian 2012; McCright 2010), and are more likely to participate in pro-environmental behaviours (Luchs and Mooradian 2012; Zelezny et al. 2000) and that these relationships occur crossnationally (Riley et al. 2012). Others, however, suggest that "perhaps personality mediates the effect of gender on sustainable consumer behaviour" in explaining gender differences in sustainability (Desochers et al. 2019; Gifford and Nilsson 2014, p. 147).

This gender gap in sustainability can be attributed to females being more considerate of others, more cautious and more responsive to negative data (Meyers-Levy and Loken 2015), more concerned about threatening situations harming their children (Toufexis et al. 2006), and more prosocial, altruistic, and empathetic than men (Dietz et al. 2002). Females have higher levels of socialisation to be caring (Zelezny et al. 2000) and are more inclined to adopt a future time perspective (Eisler and Eisler 1994). Additionally, sustainable products tend to be targeted at females within the home (e.g., food preparation, cleaning, and laundry) by utilising more feminine traits, such as caring for the environment (Brough et al. 2016). This study suggests that these results will hold with an older population and females will have an even stronger relationship between 
personality, FTP, and sustainable behaviours than males, and proposes the following hypothesis:

H5: The relationships between the personality traits, future time perspective, and sustainable behaviours are stronger for senior females than males.

\section{METHODOLOGY}

\section{Measures}

The questionnaire included scale items to measure sustainable behaviours, personality, and time perspective. To measure sustainable behaviours, we used the Roberts (1996) Ecologically Conscious Consumption Behaviour scale. The original ECCB scale is made up of 30 items, but we utilise the shorter 10-item version of the scale per Gordon-Wilson and Modi (2015), which eliminates redundant items and items that are product-specific or relate to money-saving behaviours. Others have utilised condensed versions of the ECCB scale (e.g., Riley et al. 2012) to reduce redundant items. These items capture conscious choices with sustainable behaviours, such as with product choice, limiting use of scarce resources (such as electricity), reducing pollution and environmental damage, and recycling and convincing others not to buy products harmful to the environment. The scale items were measured on a five-point Likert scale $(1=$ Always True, $5=$ Never True $)$. To measure personality, the Big 5 personality scale is utilised per Gosling et al. (2003). This scale measured on a five-point Likert scale $(1=$ Strongly Agree, $5=$ Strongly Disagree $)$ and has been used in previous studies (Gordon-Wilson and Modi 2015; Luchs and Mooradian 2012). Future time perspective is measured using the four items of Shipp et al.'s (2009) temporal focus scale. The items of the future time perspective scale were measured on a five-point Likert scale $(1=$ Strongly Agree, $5=$ Strongly Disagree). This measure overcomes the psychometric weaknesses found in other time perspective scales (Grühn et al. 2016; Shipp et al. 2009). The need for time measures with demonstrated reliability and validity has been stressed in the literature (Fung and Isaacowitz 2016). All the scale items used in the study can be found in Table 1.

Common method bias is a serious concern for researchers studying human behaviour (Podsakoff et al. 2003). It can confound true relationships between substantive constructs (Ganster et al. 1983). The method bias is a particularly significant concern for studies on environmental behaviours and attitudes (Kvasova 2015). To capture the method variance, we embedded in the questionnaire a marker variable (Lindell and Whitney 2001; Williams et al. 2010) that was theoretically uncorrelated with the focal constructs of the study. The marker variable measured the respondents' perceptions of the safety of their neighbourhood on a scale of 1 to 5 with 1 meaning "very unsafe" and 5 meaning "very safe." Additionally, respondents were assured anonymity and confidentiality of their answers to alleviate the tendency to provide socially desirable responses (Chung and Monroe 2003).

The survey was pretested within an MBA class of non-traditional students as part of a class activity addressing survey development. Students were asked if any item was problematic or if there was any difficulty faced completing the survey. No issues or problems were reported with the survey, and it took less than 10 min to complete.

Sample

The sample is made up of a Qualtrics panel of American seniors, age 50+, who have access to the Internet on their computers or mobile phones. A minimum age of 50 is utilised because this is the age needed to be members of the American Association of Retired People (join.aarp.org). The age of 50 for seniors has been utilised in the literature 
(Gordon-Wilson and Modi 2015; Guiot 2001; Kohlbacher et al. 2011; Riley et al. 2012; Sudbury and Simcock 2009). While the digital divide has been discussed as an issue in the past for seniors (Eastman and Iyer 2004), this is less of an issue currently because seniors (the 50+ age group) are the fastest-growing demographic online and the majority have shopped, searched, watched media, and/or done surveys online (Weigelt 2015b). We got 520 completed responses from American seniors.

The sample was $40 \%$ male and $60 \%$ female; the majority were Caucasian ( $83 \%$ ) followed by African-Americans (11\%). In comparing the sample to the demographics of Americans over 50 years old (54\% are female, $75 \%$ are Caucasian, and $10 \%$ are African American) (Anderson 2014), the sample corresponded with national demographics. The average age of respondents was 61 years with the youngest respondent being 50 years old and the oldest being 88 years old. As the survey was administered online, most of the respondents were in their $50 \mathrm{~s}, 60 \mathrm{~s}$, or $70 \mathrm{~s}$, reflecting national trends, whereby seniors aged 50-59 years old were considered the most tech-savvy and $57 \%$ of seniors over 70 years old were online (Anderson 2014). Finally, the sample was well represented in terms of other demographic variables such as education, life-stage, and employment status.

\section{RESULTS}

The future time perspective scale was put through a confirmatory factor analysis using maximum likelihood estimation method in AMOS 22.0 software. The scale produced a good fit with the data (chi-square $36.57, d f=2, p$ value $0.00, \mathrm{CFI}=0.97$, TLI $=0.91$, SRMR $=0.03$, RMSEA $=0.18$ ). The Gordon-Wilson and Modi (2015) version of the Roberts' (1996) ECCB scale produced an acceptable fit (chi-square 223.96, $d f=44, p$ value 0.00, $\mathrm{CFI}=0.95, \mathrm{TLI}=0.94, \mathrm{RMSEA}=0.089, \mathrm{SRMR}=0.04)$. We decided to remove one item from the scale (to save energy, I drive my car as little as possible) as it probably reflected thrift rather than sustainable behaviour. As this item had a low factor loading (0.38) and variance extraction (0.15), the item was dropped, and the scale was reanalysed. This significantly improved the fit (chi-square 159.07, $d f=35, p$ value 0.00, CFI $=0.96, \mathrm{TLI}=0.95, \mathrm{SRMR}=0.03, \mathrm{RMSEA}=0.083)$. The reduction in chi-square value $(64.89)$ was significant $(p<.01)$ for the loss of 9 degrees of freedom, and this scale was retained for further analysis.

To test our hypothesised model (Fig. 1) relating personality traits and future time perspective with sustainable behaviours, we used structural equation modelling (SEM) with maximum likelihood estimation method (AMOS 22 version). The data validated our theoretical model by producing an acceptable fit between the model implied population covariance and observed sample covariance (chi-square $=459.39, d f=162, \mathrm{CFI}=0.94$, $\mathrm{TLI}=0.93, \mathrm{SRMR}=0.049$, RMSEA $=0.059$ [CI 0.053-0.066]). All but one hypothesis (H2b) was empirically supported. The model explains $25 \%$ of the variance in sustainable behaviours and $16 \%$ of the variance in future time perspective. Table 2 below lists the standardised path coefficients of the structural model alongside the measured marker variable method bias-corrected and unmeasured latent method construct corrected path coefficients.

As a measure of robustness check for the structural path coefficients, we ran an alternative model containing direct effects of the marker variable on the scale indicators to capture any variance attributable to the method bias. The bias-corrected model (chisquare $=440.82, d f=144, \mathrm{CFI}=0.94, \mathrm{TLI}=0.92, \mathrm{SRMR}=0.048, \mathrm{RMSEA}=0.063 \quad[\mathrm{CI}$ 0.056-0.070]) path coefficients are the same in magnitude and direction. The reduced chisquare value 18.57 is gained at the loss of 18 degrees of freedom. The chi-square difference 
test shows that the $p$ value is not significant $(p=0.42)$. This indicates that the method bias does not significantly contaminate the data, and the path coefficients could be attributed to the trait variance.

Our analysis finds that FTP $(H 1)$, agreeableness $(H 2 a)$, and openness $(H 2 c)$ traits positively influence sustainable behaviours. Contrary to our expectation, we found no significant relationship between the conscientiousness personality trait and sustainable behaviours $(H 2 b)$. All three personality traits, agreeableness $(H 3 a)$, conscientiousness $(\mathrm{H} 3 \mathrm{~b})$, and openness $(\mathrm{H} 3 \mathrm{c})$ are positively related to future time perspective. The openness personality trait has the strongest impact on sustainable behaviours. By implication of the first three hypotheses, we expect FTP to partially mediate the impact of the three personality traits on sustainable behaviours (H4), which finds empirical support from the data. Seniors' FTP partially mediates the impact of agreeableness and openness personality traits on sustainable behaviours and fully mediates the impact of the conscientiousness trait on sustainable behaviours. Table 3 below provides decomposition of the standardised total effects into direct and indirect effects.

As a robustness check, we ran an alternative nested model without the mediation effect and compared the model fit with that of the hypothesised model using the chi-square difference test. The no-mediation effect model produced a poor fit with the data (chisquare $=528.69, d f=165, \mathrm{CFI}=0.93, \mathrm{TLI}=0.92, \mathrm{SRMR}=0.082, \mathrm{RMSEA}=0.065$ [CI 0.059-0.071]). Against the no-mediation effect model, our mediation effect model leads to a reduction of 69.3 chi-square value at the loss of 3 degrees of freedom which is highly significant at $p<0.001$ providing additional support to $H 4$.

To test the gender hypothesis (H5), we ran the multi-group analysis in AMOS to test the moderation effect of gender on the hypothesised relationships (see Table 4 below for separate path relationship estimates for male and female groups). First, we estimated the two group unconstrained multi-group model (A) to calculate the chi-square value and degrees of freedom (chi-square $=580.936, d f=288$ ) and compared it with the constrained multi-group model (B) (the regression weights constrained equal across the groups) using the chi-square difference test (chi-square $=615.896, d f=309$ ). The unconstrained model (A) led to a drop in the chi-square value by 34.96 points for the loss of 21 degrees of freedom. The chi-square difference test was significant at $p<0.05$, indicating that one or more regression weights differed across the groups. To identify the specific structural paths that differed across the male and female groups, we compared the unconstrained model (A) with a series of constrained models wherein one unique structural path was constrained to equal across the groups. These models were tested for the significant path differences across the male and female groups using the chi-square difference test. A significant chi-square difference indicates that the regression weight varies significantly across the two groups. Table 5 below provides the model comparison details.

We found that gender moderates only the conscientiousness and sustainable behaviour path relationship such that it is stronger in the male group. This path relationship, however, is nonsignificant in the overall sample most likely due to the suppression effect of the moderator. The remaining path relations are not significantly different across the gender groups; hence, failing to support our gender difference hypothesis (H5).

\section{DISCUSSION}

In summary, we did find support for the hypothesis linking FTP's impact on sustainable behaviours (H1). These results make sense given that existing literature suggests that consumers perceive the environmental aspect of sustainability as being more long-term 
(Catlin et al. 2017). In terms of personality, we found support that the personality traits of agreeableness $(\mathrm{H} 2 \mathrm{a})$ and openness $(\mathrm{H} 2 \mathrm{c})$ are related to performing more sustainable behaviours. There is support in the literature for both these personality variables being related to sustainable behaviours (Gordon-Wilson and Modi 2015; Luchs and Mooradian 2012) and with a senior sample (Gordon-Wilson and Modi 2015). While we did not find support in terms of conscientiousness (H2b), those studies that have found a link (e.g., Hirsh 2010; Kim et al. 2014; Kvasova 2015; Milfont and Sibley 2012; Swami et al. 2011) were not looking at a senior sample. In terms of personality's relation with FTP, we found support that agreeableness (H3a), conscientiousness (H3b), and openness (H3c) were all positively related to FTP. This finding builds on the time perspective literature by providing replication of the impact of conscientiousness on FTP (Shipp et al. 2009; Zimbardo and Boyd 1999) while providing additional support for agreeableness and openness. FTP influences sustainable behaviours directly while also acting as a partial mediator of the personality traits' influence on sustainable behaviours (H4). Finally, when exploring the role of gender (H5), although we were unable to find support for the moderating impact of gender overall, gender was found to be a moderator of conscientiousness and sustainable behaviours and this was stronger for males. While the literature has found females are more likely to participate in pro-environmental behaviours (Luchs and Mooradian 2012; Riley et al. 2012; Zelezny et al. 2000), it also suggests that these gender results may be explained by personality differences (Desrochers et al. 2019; Gifford and Nilsson 2014). This result is surprising because extant literature shows females are more conscientious than males (Costa et al. 2001; Feingold 1994; Lehmann et al. 2013; Vianello et al. 2013) and within sustainability (Desrochers et al. 2019). Our results show that this relationship is actually reversed for seniors within sustainability. Our research suggests that seniors who are motivated by sustainability can be encouraged to adopt sustainable behaviours through their FTP and personality, which offers public policymakers a means to encourage sustainability efforts beyond demographics. Senior Americans with a FTP are more likely to adopt sustainable behaviours. Seniors with a FTP may be especially able to recognise the benefits of their sustainable behaviours even if the direct impact is not immediately experienced (Wei et al. 2013). Additionally, our research suggests that older adults have a higher level of self-continuity and are more likely to see the relationship between the present and the future (Fung and Isaacowitz 2016; Rutt and Löckenhoff 2016). Personality traits, particularly openness and agreeableness, also positively impacted seniors' sustainable behaviour. The results suggest that seniors who plan for the future are open to new experiences and are more agreeable to make compromises with their own needs that are more likely to adopt more sustainable behaviours. The implications of this for public policymakers are discussed in the next section.

\section{Theoretical and Public Policy Implications}

Given that seniors represent a higher environmental burden (Kalbar et al. 2018), gaining a better understanding of what impacts their sustainability behaviours is vital. The size and scope of the senior market in the USA (Anderson 2014; Weigelt 2015a), and the increased longevity of seniors (BBC News 2019), along with the large environmental footprint of Americans (EDGAR 2017), suggests the necessity of looking specifically at the senior market within the USA. The findings of this study looking at FTP and personality contributes to our understanding of sustainability behaviours in the literature and suggests means for public policymakers to increase seniors' sustainability efforts. 
This research contributes to SST by demonstrating that how seniors see time impacts their sustainable behaviours. Additionally, while the literature on SST suggests that seniors are more present- and less future-oriented, our results suggest that seniors with FTP are more likely to adopt more sustainable behaviours. Additionally, our research contributes to existing literature by showing that the openness and agreeableness personality traits positively impact on sustainable behaviours. This suggests that seniors who are more open to new experiences and who are more willing to compromise to get along may be more receptive to adopting sustainable behaviours when encouraged by public policymakers. The relationship between openness, agreeableness, and conscientiousness with FTP suggests that seniors' personality can influence how they see time. This will help to inform consumer policy makers when persuading seniors to adopt more sustainable behaviours. Messages should convey that society can be helped in the future (FTP) by seniors making compromises (agreeableness) to be better organised and vigilant (conscientiousness) by adopting new and different sustainable behaviours (openness).

Our research extends the findings of Milfont et al. (2012) to a national senior sample in the USA. As our research found that seniors with more of a FTP report performing more sustainable behaviours and the literature notes that those with a FTP focus on more knowledge-oriented goals (Carstensen et al. 1999), we offer the following recommendations for public policymakers. We recommend that consumer policy empowers people so they can make informed choices (Austgulen 2014, 2016; Gandenberger et al. 2011; Hansen and Schrader 1997; Thøgersen 2005) that will inevitably lead to them increasing their sustainable behaviours, so it becomes a natural part of their daily lives. Given the size and scope of the senior market (Anderson 2014), we offer that this knowledge to empower seniors with how to be more sustainable is even more critical. When referring to the ECCB scale (Roberts 1996) used in this research, public policy could educate and guide seniors about how they can make more sustainable choices, such as choosing products with the least amount of pollution (e.g., purchasing electric vehicles) and limiting the usage of products containing scarce resources (e.g., choosing to take showers over baths to help conserve water), along with always recycling their household rubbish. This could be communicated via consumer interest groups such as AARP. Seniors would be encouraged to be more responsible by making more sustainable choices and consistently adopting sustainable behaviours such as recycling. These are small, manageable, and therefore achievable changes, so they are more likely to receive support from seniors than any radical policies involving a significant behavioural change.

Theoretically, our personality findings provide additional support to the literature of the importance of the Big 5 personality variables on impacting sustainability (Gifford and Nilsson 2014; Luchs and Mooradian 2012; Milfont and Sibley 2012), through our focus on a senior-specific sample in the USA. As there was a direct link between the personality traits of openness and agreeableness, we recommend that public policy makers praise seniors and provide feedback about the impact of their changes (e.g., helping to make a positive contribution to the environment and the planet). Utilising their openness to try new things, along with their concern and sympathy for others, will initially help to keep them motivated and then actively engaged as they get reinforcement that their efforts are making a difference. This could be done on the community level by illustrating the impact of the community's sustainability efforts.

Given that the personality traits of openness, conscientiousness, and agreeableness influence FTP, we recommend that public policy makers provide information with knowledge goals of making a difference to attract more future-focused seniors with a message of how their sustainable behaviours can have a positive impact. As current- and 
future-focused consumers tend to be more positive (Shipp et al. 2009), we recommend that these messages should be focused on the positive aspects of sustainable behaviours, illustrating the impact of being more sustainable rather than fear or the negative aspects of hurting the environment by not adopting sustainable behaviours. These positive messages need to be attractive to seniors with open, conscientious, and/or agreeable personality types through illustrating how being willing to do something different and making an organised consistent effort can help others in the community now and in the future. Thus, governments, businesses, policy makers, environmental groups, charities, and the media should persuade American seniors to adopt sustainable behaviours and to integrate them into their lives by representing their benefits in the future. This can be done through education, the media, marketing, visiting, and speaking at senior community groups to facilitate discussion, enlisting senior role models acting as "Sustainable Ambassadors" to endorse sustainable living, and by encouraging immersion into sustainable projects and initiatives.

Finally as we did not find an overall gender difference, the results suggest that public policymakers should target both men and women with their sustainability efforts. This finding builds on the work done by Desochers et al. (2019) by extending it to a seniorspecific sample in the USA.

\section{Limitations and Future Research}

Our research examined what impacted sustainable behaviours, so the elderly respondents needed to be living independently and an online sample better captured this. Most of the respondents were under 70 , as the survey was online. While the national sample of seniors related well to the demographic characteristics of seniors in America, future research would need to compare the results with an older-old sample of seniors age $75+$ to see what differences there are between the groups, particularly as the older-old may have a lower FTP (Shipp et al. 2009). Future research is also needed to examine how the relationships found in this study may vary in different countries, as research suggests that social and cultural contexts along with life experiences may impact how seniors respond (Guido et al. 2014; Kohlbacher et al. 2011).

Given the complexity of sustainable behaviours (Gifford and Nilsson 2014), there are many potential areas of future research in further understanding the senior market and sustainability. Future research could examine additional variables that may illuminate how a future time perspective influences sustainability behaviours. This could include looking at altruism and family structure to see if concern for younger relatives could positively impact sustainability behaviours to improve the environment. Our study uses self-reported behavioural data of American seniors. Future research could use experimental data to study sustainable behaviour of seniors, such as testing the effectiveness of different sustainability messages on sustainability intentions for seniors. Additionally, research could build on these results through utilisation of additional measures of personality and time. Research is also needed to see if the results found in this study with ECCB hold with more socially sustainable behaviours as the literature suggests social sustainability to be more of a short-term affective consideration (Catlin et al. 2017). Finally, another area of future research would be to determine what impact specific life situations of seniors, such as illness, frustration, and economic conditions (Fung et al. 1999), have on the FTP sustainability link. As negative life situations may impact seniors' perceptions of agerelated loss and well-being, they could impact the FTP of seniors (Brothers et al. 2016).

\section{CONCLUSION}


This study of a national sample of American seniors age 50 years old or older found a link between three personality types, time perspective, and sustainable behaviours. Specifically, seniors having agreeableness and openness personality traits exhibited more sustainable behaviours. Also, their future time perspective partially mediated the impact of the agreeableness, conscientiousness, and openness personality traits on sustainable behaviours. These results suggest that any policy that is aimed at encouraging the adoption of sustainable behaviour by American seniors should prioritise the more open, conscientious, and agreeable consumers who focus on the future, while using knowledge goals to attract these future-oriented consumers.

Publisher's Note

\section{References}

Allemand, M., Hill, P. L., Ghaemmagham, P., \& Martin, M. (2012). Forgivingness and subjective well-being in adulthood: The moderating role of future time perspective. Journal of Research in Personality, 4, 32-39.

Anderson, G. (2014). Getting to know Americans age 50+. AARP Research. http://www.aarp.org/research/topics/life/info-2014/getting-to-know-americans-age-50.html. .

Austgulen, M. H. (2014). Environmentally sustainable meat consumption: An analysis of the Norwegian public debate. Journal of Consumer Policy, 37, 45-66.

Austgulen, M. H. (2016). Environmentally sustainable textile consumption: What characterizes the political textile consumers. Journal of Consumer Policy, 39, 441-466.

Baars, J. (2010). Time and aging: Enduring and emerging issues. In D. Dannefer \& C. Phillpson (Eds.), The SAGE handbook of social gerontology (pp. 367-376). London: Sage.

Barber, S. J., Opitz, P. C., Martins, B., Sakaki, M., \& Mather, M. (2016). Thinking about a limited future enhances the positivity of younger and older adults' recall: Support for socioemotional selectivity theory. Memory \& Cognition, 44(6), 869-882.

BBC News (2019). How long are you going to live? https://www.bbc.co.uk/news/av/business-47527765/how-long-are-you-going-tolive . Accessed 15 Nov 2019.

Brothers, A., Gabrian, M., Wahl, H.-W., \& Diehl, M. (2016). Future time perspective and awareness of age-related change: Examining their role in predicting psychological wellbeing. Psychology and Aging, 31(6), 605-617.

Brough, A. R., Wilkie, J. E. B., Ma, J., Isaac, M. S., \& Gal, D. (2016). Is eco-friendly unmanly? The green-feminine stereotype and its effect on sustainable consumption. Journal of Consumer Research, 43(4), 567-582.

Carlsson-Kanyama, A., Julia, I., \& Röhr, U. (2010). Unequal representation of women and men in energy company boards and management groups: Are there implications for mitigation? Energy Policy, 38, 4737-4740.

Carmi, N. (2013). Caring about tomorrow: Future orientation, environmental attitudes and behaviours. Environmental Education Research, 19(4), 430-444. 
Carstensen, L. L., Isaacowitz, D. M., \& Charles, S. T. (1999). Taking time seriously: A theory of socioemotional selectivity. American Psychologist, 54(3), 165-181.

Carstensen, L. L., Turan, B., Scheibe, S., Ram, N., Ersner-Hersfield, H., Samanez-Larkin, G. R., \& Nesselroade, J. R. (2011). Emotional experience improves with age: Evidence based on over 10 years of experience sampling. Psychology and Aging, 26, 21-33.

Catlin, J. R., Luchs, M. G., \& Phipps, M. (2017). Consumer perceptions of the social vs. environmental dimensions of sustainability. Journal of Consumer Policy, 40, 245-277.

Chung, J., \& Monroe, G. S. (2003). Exploring social desirability bias. Journal of Business Ethics, 44(4), 291-302.

Corral-Verdugo, V., Fraijo-Sing, B., \& Pinheiro, J. Q. (2006). Sustainable behaviour and time perspective: Present, past, and future orientations and their relationship with water conservation behaviour. Interamerican Journal of Psychology, 40(2), 139-147.

Costa Jr., P. T., Terracciano, A., \& McCrae, R. R. (2001). Gender differences in personality traits across cultures: Robust and surprising findings. Journal of Personality and Social Psychology, 81, 322-331.

Coudin, G., \& Lima, M. L. (2011). Being well as time goes by: Future time perspective and well-being. International Journal of Psychology and Psychological Therapy, 11, $219-$ 232.

Desochers, J. E., Albert, G., Milfont, T. L., Kelly, B., \& Arnocky, S. (2019). Does personality mediate the relationship between sex and environmentalism? Personality and Individual Differences, 147, 204-213.

DeYoung, C. G. (2010). Impulsivity as a personality trait. In K. D. Vohs \& R. F. Baumeister (Eds.), Handbook of self-regulation: Research, theory, and applications (2nd ed., pp. 485-502). New York: Guilford Press.

Diamantopoulos, A., Schlegelmilch, B. B., Sinkovics, R. R., \& Bohlen, G. M. (2003). Can sociodemographics still play a role in profiling green consumers? A review of the evidence and an empirical investigation. Journal of Business Research, 56(6), 465-480.

Dietz, T., Kalof, L., \& Stern, P. C. (2002). Gender, values, and environmentalism. Social Science Quarterly, 83, 353-364.

Eastman, J. K., \& Iyer, R. (2004). The elderly's uses and attitudes towards the internet. Journal of Consumer Marketing, 21(3), 208-220.

Ebner, N. C. (2006). Developmental changes in personal goal orientation from young to late adulthood: From striving for gains to maintenance and prevention of losses. Psychology and Aging, 21, 664-678.

Eckhardt, G. M. (2010). Why don't consumers consume ethically? Journal of Consumer Behaviour, 9(6), 167-181.

EDGAR (Emissions Database for Global Atmospheric Research) (2017). http://edgar.jrc.ec.europa.eu/overview.php?v=CO2andGHG19702016\&sort=des9 . Accessed 15 Nov 2019.

Eisler, A. D., \& Eisler, H. (1994). Subjective time scaling: Influence of age, gender, and type A and type B behaviour. Chronobiologia, 21(3-4), 185-200. 
Feingold, A. (1994). Gender differences in personality: A meta-analysis. Psychological Bulletin, 116, 429-456.

Finisterra do Paço, A. M., \& Raposo, M. L. B. (2010). Green consumer market segmentation: Empirical findings from Portugal. International Journal of Consumer Studies, 34(4), 429-436.

Fung, H. H., \& Carstensen, L. L. (2003). Sending memorable messages to the old: Age differences in preferences and memory for advertisements. Journal of Personality and Social Psychology, 85(1), 163-178.

Fung, H. H., \& Isaacowitz, D. M. (2016). The role of time and time perspective in agerelated processes: Introduction to the special issue. Pyschology and Aging, 31(6), 553557.

Fung, H. H., Carstensen, L. L., \& Lutz, A. M. (1999). Influence of time on social preferences: Implications for life-span development. Psychology and Aging, 14(4), 595604.

Gandenberger, C., Garrelts, H., \& Wehlau, D. (2011). Assessing the effects of certification networks on sustainable production and consumption: The cases of FLO and FSC. Journal of Consumer Policy, 34, 107-126.

Ganster, D., Hennessey, H., \& Luthans, F. (1983). Social desirability response effects: Three alternative models. Academy of Management Journal, 26, 321-331.

Gardner, G. T., \& Stern, P. C. (2008). The short list: The most effective actions U.S. households can take to curb climate change. Environment, 50(5), 12-24.

GFK. (2011) The Environment: Public Attitudes and Individual Behaviour- A TwentyYear

Evolution. https:/ekotrope.com/wpcontent/uploads/2011/12/SCJ+and+GfK+Roper+Gree n+Gauge.pdf . Accessed 15 Nov 2019.

Gifford, R., \& Nilsson, A. (2014). Personal and social factors that influence proenvironmental concern and behaviour: A review. International Journal of Psychology, 49(3), 141-157.

Gordon-Wilson, S., \& Modi, P. (2015). Personality and older consumers' green behaviour in the UK. Futures, 71, 1-10.

Gosling, S. D., Rentfrow, P. J., \& Swann Jr., W. B. (2003). A very brief measure of the big five personality domains. Journal of Research in Personality, 37, 504-528.

Gregory, L. D. (2014). Fundraising and the elderly: A content analysis. Journal of Consumer Policy, 37, 5-25.

Grühn, D., Sharifian, N., \& Chu, Q. (2016). The limits of a limited future time perspective in explaining age differences in emotional functioning. Psychology and Aging, 31, 583593.

Guido, G., Amatulli, C., \& Peluso, A. M. (2014). Context effects on older consumers' cognitive age: The role of hedonic versus utilitarian goals. Psychology and Marketing, 31(2), 103-114. 
Guiot, D. (2001). Antecedents of subjective age biases among senior women. Psychology and Marketing, 18(10), 1049-1071.

Hansen, U., \& Schrader, U. (1997). A modern model of consumption for a sustainable society. Journal of Consumer Policy, 20, 443-468.

Hirsh, J. B. (2010). Personality and environmental concern. Journal of Environmental Psychology, 30, 245-248.

Hirsh, J. B., \& Dolderman, D. (2007). Personality predictors of consumerism and environmentalism: A preliminary study. Personality and Individual Differences, 43(6), 1583-1593.

Jacques, P. H., Garger, J., Brown, C. A., \& Deale, C. S. (2009). Personality and virtual reality team candidates: The roles of personality traits, technology anxiety and trust as predictors of perceptions of virtual reality teams. Journal of Business and Management, $15,143-157$.

John, O.P. \& Srivastava, S. (1999). The big-five trait taxonomy: History, measurement, and theoretical perspectives. In L.A. Pervin \& O.P. John (Vol. Eds). Handbook of personality: Theory and research. Vol 2. (pp. 102-138). New York, NY: Guilford Press.

Joireman, J. A., Van Lange, P. A., \& Van Vugt, M. (2004). Who cares about the environmental impact of cars? Those with an eye toward the future. Environment and Behavior, 36(2), 187-206.

Kalbar, P. P., Birkved, M., Hauschild, M., \& Kabins, S. (2018). Environmental impact of urban consumption patterns: Drivers and focus points. Resources, Conservation and Recycling, 137, 260-269.

Kennedy, Q., Mather, M., \& Carstensen, L. L. (2004). The role of motivation in the agerelated positivity effect in autobiographical memory. Psychological Science, 15, 208-214.

Kilbourne, W. E., \& Pickett, G. (2008). How materialism affects environmental beliefs, concern, and environmentally-responsible behaviour. Journal of Business Research, 61(10), 1-9.

Kilbourne, W. E., Beckmann, S. C., \& Thelen, E. (2002). The role of the dominant social paradigm in environmental attitudes: A multinational examination. Journal of Business Research, 55(3), 193-204.

Kim, J., Schmöcker, J.-D., Bergstad, C. J., Fujii, S., \& Gärling, T. (2014). The influence of personality on acceptability of transport policies. Transportation, 41, 855-872.

Kohlbacher, F., Riley, L. S., \& Hofmeister, A. (2011). Challenging the culture-free hypothesis of cognitive age among older consumers: Evidence from a cross-national survey. Advances in Consumer Research, 39, 325.

Kotter-Grühn, D., Grühn, D., \& Smith, J. (2010). Predicting one's own death: The relationship between subjective and objective nearness to death in very old age. European Journal of Ageing, 7, 293-300.

Kuppelwieser, V. G., \& Sarstedt, M. (2015). Exploring the influence of customers' time horizon perspectives on the satisfaction-loyalty link. Journal of Business Research, 67(12), 2620-2627. 
Kvasova, O. (2015). The big five personality traits as antecedents of eco-friendly tourist behaviour. Personality and Individual Differences, 83, 111-116.

Lang, F. R., \& Carstensen, L. L. (2002). Time counts: Future time perspective, goals, and social relationships. Psychology and Aging, 17, 125-139.

Lehmann, R., Denissen, J. J., Allemand, M., \& Penke, L. (2013). Age and gender differences in motivational manifestations of the big five from age 16 to 60. Developmental Psychology, 49, 365-383.

Lindell, M. K., \& Whitney, D. J. (2001). Accounting for common method variance in cross-sectional research designs. Journal of Applied Psychology, 86(1), 114-121.

Löckenhoff, C. E., Reed, A. E., \& Maresca, S. N. (2012). Who saves the best for last? Age differences in preferences for affective sequences. Psychology and Aging, 27, 840-848.

Luchs, M. G., \& Mooradian, T. A. (2012). Sex, personality, and sustainable consumer behavior: Elucidating the gender effect. Journal of Consumer Policy, 35(1), 127-144.

Markowitz, E. M., Goldberg, L. R., Ashton, M. C., \& Lee, K. (2012). Profiling the "proenvironmental" individual: A personality perspective. Journal of Personality, 80(1), $81-111$.

McCrae, R. R., \& Costa, P. T. (1990). Personality in adulthood. New York, NY: Guildford Press.

McCrae, R. R., \& John, O. P. (1992). An introduction to the five-factor model and its applications. Journal of Personality, 60, 175-215.

McCright, A. M. (2010). The effects of gender on climate change knowledge and concern in the American public. Population and Environment, 32, 66-87.

Meyers-Levy, J., \& Loken, B. (2015). Revisiting gender differences: What we know and what lies ahead. Journal of Consumer Psychology, 25(1), 129-149.

Milfont, T. L., \& Sibley, C. G. (2012). The big five personality traits and environment engagement: Associations at the individual and societal level. Journal of Environmental Psychology, 32(2), 187-195.

Milfont, T. L., Wilson, J., \& Diniz, P. (2012). Time perspective and environmental engagement: A meta-analysis. International Journal of Psychology, 47(5), 325-334.

Nisbet, E. K., Zelenski, J. M., \& Murphy, S. A. (2009). The nature relatedness scale: Linking individuals' connection with nature to environmental concern and behavior. Environment and Behavior, 41(5), 715-740.

Pape, J., Rau, H., Fahy, F., \& Davies, A. (2011). Developing policies and instruments for sustainable household consumption: Irish experiences and futures. Journal of Consumer Policy, 34, 25-42.

Podsakoff, P. M., MacKenzie, S. B., Lee, J. Y., \& Podsakoff, N. P. (2003). Common method biases in behavioural research: A critical review of the literature and recommended remedies. Journal of Applied Psychology, 885, 879-903.

Riley, L. S., Kohlbacher, F., \& Hofmeister, A. (2012). A cross-cultural analysis of proenvironmental consumer behaviour among seniors. Journal of Marketing Management, 28(3-4), 290-312. 
Robelia, B., \& Murphy, T. (2012). What do people know about key environmental issues? A review of environmental knowledge surveys. Environmental Education Research, 18, 299-321.

Roberts, J. A. (1996). Green consumers in the 1990s: Profile and implications for advertising. Journal of Business Research, 36, 217-231.

Roberts, A. W., Ogunwole, S. U., Blakeslee, L., \& Rabe M. E. (2018). The population 65 years and older in the United States. https://www.census.gov/library/publications/2018/acs/acs-38.html . Accessed 15 Nov 2019.

Rutt, J. L., \& Löckenhoff, C. E. (2016). From past to future: Temporal self-continuity across the life span. Psychology and Aging, 31, 631-639.

Shipp, A. J., \& Aeon, B. (2019). Temporal focus: Thinking about the past, present, and future. Current Opinion in Pyschology, 26, 37-43.

Shipp, A. J., Edwards, J. R., \& Lambert, L. S. (2009). Conceptualization and measurement of temporal focus: The subjective experience of the past, present, and future. Organizational Behaviour and Human Decision Processes, 110, 1-22.

Soliño, M., \& Farizo, B. A. (2014). Personal traits underlying environmental preferences: A discrete choice experiment. PLoS ONE, e89603. https://doi.org/10.1371/journal.pone.0089603 .

Sudbury, L., \& Simcock, P. (2009). Understanding older consumers through cognitive age and the list of values: A U.K. based perspective. Psychology and Marketing, 26(1), 2238 .

Swami, V., Chamorro-Premuzic, T., Snelgar, R., \& Furnham, A. (2011). Personality, individual differences, and demographic antecedents of self-reported household waste management behaviours. Journal of Environmental Psychology, 31, 21-26.

Thøgersen, J. (2005). How may consumer policy empower consumers for sustainable lifestyles? Journal of Consumer Policy, 28, 143-178.

Thøgersen, J., \& Crompton, T. (2009). Simple and painless? The limitations of spillover in environmental campaigning. Journal of Consumer Policy, 32, 141-163.

Toufexis, D. J., Myers, K. M., \& Davis, M. (2006). The effect of gonadal hormones and gender on anxiety and emotional learning. Hormones and Behaviour, 50(4), 539-549.

Urien, B., \& Kilbourne, W. (2011). Generativity and self enhancement values in ecofriendly behavioural intentions and environmentally responsible consumption behaviour. Psychology and Marketing, 28, 69-90.

Valor, C. (2008). Can consumers buy responsibly? Analysis and solutions for market failure. Journal of Consumer Policy, 31, 315-326.

Verplanken, B., \& Sato, A. (2011). The psychology of impulse buying: An integrative self-regulation approach. Journal of Consumer Policy, 34, 197-210.

Vianello, M., Schnabel, K., Sriram, N., \& Nosek, B. (2013). Gender differences in implicit and explicit personality traits. Personality and Individual Differences, 55, 994-999. 
Wei, Y., Donthu, N., \& Bernhardt, K. L. (2013). Effects of cognitive age, dispositional time perceptions, and time view manipulations on product attribute evaluations. Journal of Business Research, 66, 2171-2177.

Weigelt, D. (2015a). 50+ facts and fiction: Size, wealth, and spending of 50+ consumers. Immersion Active, https://www.immersionactive.com/resources/size-wealthspending-50-consumers . Accessed 15 November 2019.

Weigelt, D. (2015b). 50+ facts and fiction: Mature consumers online. Immersion Active, https://www.immersionactive.com/resources/50-consumers-online . Accessed 15 Nov 2019.

Wiernik, B. M., Dilchert, S., \& Ones, D. S. (2016). Age and employee green behaviours: A meta-analysis. Frontiers in Pyschology, 7, 1-15.

Williams, P., \& Drolet, A. (2005). Age-related differences in responses to emotional advertisements. Journal of Consumer Research, 32(3), 343-354.

Williams, L., Hartman, N., \& Cavazotte, F. (2010). Method variance and marker variable: A review and comprehensive CFA marker technique. Organizational Research Methods, 13(3), 477-514.

Wood, S. (2012). Prone to progress: Using personality to identify supporters of innovative social entrepreneurship. Journal of Public Policy \& Marketing, 31(1), 129-141.

Xiao, C., \& McCright, A. M. (2015). Gender differences in environmental concern: Revisiting the institutional trust hypothesis in the USA. Environment and Behavior, 47, $17-37$.

Youn, S., \& Faber, R. J. (2000). Impulse buying: Its relation to personality traits and cues. Advances in Consumer Research, 27, 179-185.

Zelezny, L. C., Chua, P.-P., \& Aldrich, C. (2000). Elaborating on gender differences in environmentalism. Journal of Social Issues, 56(3), 443-457.

Zimbardo, P. G., \& Boyd, J. N. (1999). Putting time in perspective: A valid, reliable individual-differences metric. Journal of Personality and Social Psychology, 77, 12711288. 


\section{Table 1}

Constructs, measurement scales and sources

\begin{tabular}{|l|l|l|}
\hline Construct & Scale & Scale items \\
\hline $\begin{array}{l}\text { Sustainable } \\
\text { behaviours }\end{array}$ & $\begin{array}{l}\text { Ecologically conscious } \\
\text { consumption behaviour } \\
\text { (Roberts 1996 shortened } \\
\text { by Gordon-Wilson and } \\
\text { Modi 2015) }\end{array}$ & $\begin{array}{l}\text { When there is a choice, I always choose that product which contributes to the least amount of pollution. } \\
\text { If I understand the potential damage to the environment that some products can cause, I do not purchase these } \\
\text { I have purchased a household appliance because it uses less electricity than other brands. } \\
\text { I have purchased products because they cause less pollution. } \\
\text { When I have a choice between two equal products, I always purchase the one which is less harmful to other people } \\
\text { and the environment. } \\
\text { I will not buy a product if the company that sells it is ecologically irresponsible. }\end{array}$ \\
\hline
\end{tabular}




\begin{tabular}{|c|c|c|}
\hline & & $\begin{array}{l}\text { I normally make a conscious effort to limit my use of products that are made of or use scarce resources. } \\
\text { I use a recycling centre or in some way recycle some of my household trash. }\end{array}$ \\
\hline Personality & $\begin{array}{l}\text { Big } 5 \text { personality scale } \\
\text { (adapted by Gosling et } \\
\text { al. 2003) }\end{array}$ & $\begin{array}{l}\text { I see myself as an extraverted and enthusiastic person. } \\
\text { I see myself as a reserved and quiet person. } \\
\text { I see myself as a person open to new experiences in life. } \\
\text { I see myself as conventional, uncreative person. } \\
\text { I see myself as a sympathetic and warm person. } \\
\text { I see myself as a critical and quarrelsome person. } \\
\text { I see myself as a dependable and self-disciplined person. } \\
\text { I see myself as a disorganised and careless person. } \\
\text { I see myself as a calm and emotionally stable person. } \\
\text { I see myself as an anxious and easily upset person. }\end{array}$ \\
\hline $\begin{array}{l}\text { Future time } \\
\text { perspective }\end{array}$ & $\begin{array}{l}\text { Temporal focus } \\
\text { scale (Shipp et al. 2009) }\end{array}$ & $\begin{array}{l}\text { I think about what my future has in store. } \\
\text { I think about times to come. } \\
\text { I focus on my future. } \\
\text { I imagine what tomorrow will bring for me. }\end{array}$ \\
\hline $\begin{array}{l}\text { Common } \\
\text { method } \\
\text { bias }\end{array}$ & $\begin{array}{l}\text { Marker } \\
\text { variable (Gordon- } \\
\text { Wilson and Modi 2015) }\end{array}$ & How safe do you think your area/neighbourhood is? \\
\hline
\end{tabular}




\section{Table 2}

Standardised path coefficients and method bias corrected path coefficients

\begin{tabular}{|c|c|c|}
\hline Hypothesised path" & Model path coefficient & $\begin{array}{l}\text { The } \\
\text { measured } \\
\text { marker varia } \\
\text { ble method } \\
\text { bias- } \\
\text { corrected } \\
\text { path coefficie } \\
\text { nts }\end{array}$ \\
\hline H1: Future time perspective $\rightarrow(+)$ sustainable behaviours & $0.17 *$ & $0.17 *$ \\
\hline H2a: Agreeableness $\rightarrow(+)$ sustainable behaviours & $0.18^{*}$ & $0.18^{*}$ \\
\hline$H 2 b:$ Conscientiousness $\rightarrow(+)$ sustainable behaviours & $-0.01^{\text {ns }}$ & $-0.008^{\mathrm{ns}}$ \\
\hline$H 2 c:$ Openness $\rightarrow(+)$ sustainable behaviours & $0.34 *$ & $0.34 *$ \\
\hline H3a: Agreeableness $\rightarrow(+)$ future time perspective & $0.19 *$ & $0.19 *$ \\
\hline$H 3 b$ : Conscientiousness $\rightarrow(+)$ future time perspective & $0.20^{*}$ & $0.20^{*}$ \\
\hline$H 3 c:$ Openness $\rightarrow(+)$ future time perspective & $0.18^{*}$ & $0.18^{*}$ \\
\hline
\end{tabular}




\section{Table 2}

Standardised path coefficients and method bias corrected path coefficients

\begin{tabular}{|l|l|l|}
\hline & & \\
Hypothesised path ${ }^{*}$ & $\begin{array}{l}\text { The } \\
\text { measured } \\
\text { marker varia } \\
\text { ble method } \\
\text { bias- } \\
\text { corrected } \\
\text { path coefficie } \\
\text { nts }\end{array}$ \\
\hline R-square sustainable behaviours & coefficient \\
\hline R-square future time perspective & 0.25 & 0.25 \\
\hline$n s$ nonsignificant & 0.16 & 0.15 \\
\hline$* p<0.05$ & \\
\hline
\end{tabular}




\section{Table 3}

Standardised direct and indirect effects of personality on sustainable behaviours

\begin{tabular}{|l|l|l|l|}
\hline & $\begin{array}{c}\text { Direct effect } \\
(\text { SB) }\end{array}$ & Indirect effect (SB) & Total effect (SB) \\
\hline Agreeableness & 0.180 & 0.032 & 0.212 \\
\hline Conscientiousness & -0.010 & 0.034 & 0.024 \\
\hline Openness & 0.342 & 0.030 & 0.373 \\
\hline
\end{tabular}




\section{Table 4}

Path relationships across male and female groups

\begin{tabular}{|l|l|l|}
\hline \multicolumn{1}{|c|}{ Hypothesised path } & \multicolumn{1}{c|}{$\begin{array}{c}\text { Standardised model path } \\
\text { coefficient (male) }\end{array}$} & $\begin{array}{c}\text { Standardised } \\
\text { model path coefficient } \\
\text { (female) }\end{array}$ \\
\hline$H 1:$ Future time perspective $\rightarrow(+)$ sustainable behaviours & $0.124^{\text {ns }}$ & $0.242^{*}$ \\
\hline$H 2 a:$ Agreeableness $\rightarrow(+)$ sustainable behaviours & $0.155^{\text {ns }}$ & $0.222^{*}$ \\
\hline$H 2 b:$ Conscientiousness $\rightarrow(+)$ sustainable behaviours & $0.126^{*}$ & $-0.183^{\text {ns }}$ \\
\hline$H 2 c:$ Openness $\rightarrow(+)$ sustainable behaviours & $0.286^{*}$ & $0.364^{*}$ \\
\hline$H 3 a:$ Agreeableness $\rightarrow(+)$ future time perspective & $0.23^{\text {ns }}$ & $0.128^{\text {ns }}$ \\
\hline$H 3 b:$ Conscientiousness $\rightarrow(+)$ future time perspective & $0.141^{*}$ & $0.277^{\text {ns }}$ \\
\hline$H 3 c:$ Openness $\rightarrow(+)$ future time perspective & $0.195^{*}$ & $0.189^{*}$ \\
\hline $\mathrm{R}-$ square future time perspective & 0.170 & 0.169 \\
\hline $\mathrm{R}-$ square sustainable behaviours & 0.236 & 0.282 \\
\hline
\end{tabular}




\section{Table 4}

Path relationships across male and female groups

\begin{tabular}{|l|l|l|}
\hline \multicolumn{1}{|c|}{ Hypothesised path } & $\begin{array}{c}\text { Standardised model path } \\
\text { coefficient (male) }\end{array}$ & $\begin{array}{c}\text { Standardised } \\
\text { model path coefficient } \\
\text { (female) }\end{array}$ \\
\hline$n s$ nonsignificant & \\
\hline$* p<0.05$ & \\
\hline
\end{tabular}




\section{Table 5}

Multi-group analysis

\begin{tabular}{|l|l|l|l|l|}
\hline \multicolumn{1}{|c|}{ Models } & \multicolumn{1}{|c|}{ Model description } & Chi-square & $\begin{array}{c}\text { Chi-square } \\
\text { Degree of } \\
\text { freedom } \\
\text { difference test } \\
\text { (difference in } \\
\text { the degree of } \\
\text { freedom) }\end{array}$ \\
\hline The unconstrained (base) model (A) & Unconstrained multi-group model & 580.936 & 288 & - \\
\hline Fully constrained model (B) & Regression weights constrained & 615.896 & 309 & $34.96^{*}(21)$ \\
\hline FTP $\rightarrow$ SB constrained model (C) & $\begin{array}{l}\text { Future time perspective } \rightarrow \text { sustainable } \\
\text { behaviours path constrained }\end{array}$ & 581.811 & 289 & $0.875^{\text {ns }}(1)$ \\
\hline Agre $\rightarrow$ SB constrained model (D) & $\begin{array}{l}\text { Agreeableness } \rightarrow \text { sustainable behaviours } \\
\text { path constrained }\end{array}$ & 581.210 & 289 & $0.274^{\text {ns }}(1)$ \\
\hline Cons $\rightarrow$ SB constrained model (E) & $\begin{array}{l}\text { Conscientiousness } \rightarrow \text { sustainable } \\
\text { behaviours path constrained }\end{array}$ & 587.204 & 289 & $6.268^{*}(1)$ \\
\hline Open $\rightarrow$ SB constrained model (F) & $\begin{array}{l}\text { Openness } \rightarrow \text { sustainable behaviours path } \\
\text { constrained }\end{array}$ & 581.571 & 289 & $0.635^{\text {ns }}(1)$ \\
\hline
\end{tabular}




\section{Table 5}

Multi-group analysis

\begin{tabular}{|l|l|l|l|l|}
\hline \multicolumn{1}{|c|}{ Models } & \multicolumn{1}{|c|}{ Model description } & Chi-square & $\begin{array}{c}\text { Chi-square } \\
\text { Degree of } \\
\text { freedom } \\
\text { difference test } \\
\text { (difference in } \\
\text { the degree of } \\
\text { freedom) }\end{array}$ \\
\hline Agre $\rightarrow$ FTP constrained model (G) & $\begin{array}{l}\text { Agreeableness } \rightarrow \text { future time perspective } \\
\text { path constrained }\end{array}$ & 583.487 & 289 & $2.551^{\text {ns }}(1)$ \\
\hline Cons $\rightarrow$ FTP constrained model (H) & $\begin{array}{l}\text { Conscientiousness } \rightarrow \text { future time } \\
\text { perspective path constrained }\end{array}$ & 582.361 & 289 & $1.425^{\text {ns }}(1)$ \\
\hline Open $\rightarrow$ FTP constrained model (I) & $\begin{array}{l}\text { Openness } \rightarrow \text { future time perspective path } \\
\text { constrained }\end{array}$ & 580.962 & 289 & $0.026^{\text {ns }}(1)$ \\
\hline$n s$ nonsignificant & & & \\
\hline$* p<0.05$ &
\end{tabular}

